\title{
Surgical Management of Dystocia in a Cross Bred Holstein Friesian Heifer by Caesarean Section- A Case Report
}

\author{
B. M. Nijin Jos* \\ Kerala Animal Husbandry Department, Veterinary Surgeon, Veterinary Dispensary, \\ Cumbummettu, Idukki, Kerala, India \\ *Corresponding author
}

\section{A B S T R A C T}

\begin{tabular}{l}
\hline Ke y w o r d s \\
$\begin{array}{l}\text { Bovine Dystocia, } \\
\text { Foetomaternal } \\
\text { disproportion, } \\
\text { Malposition, } \\
\text { Caesarean Section }\end{array}$ \\
\hline Article Info \\
\hline $\begin{array}{l}\text { Accepted: } \\
\text { 22 June } 2020 \\
\text { Available Online: } \\
\text { 10 July } 2020\end{array}$ \\
\hline
\end{tabular}

Dystocia or difficulty in parturition is a commonly seen in cattle and buffaloes among the domestic animals. The condition can occur as result of numerous factors. This condition when it occurs in a heifer, foetomaternal disproportion becomes the main causative factor. Such conditions often need a caesarean section in order to save the life of the dam. A two year old cross bred holstein friesian heifer presented with the condition of dystocia due to foeto maternal disproportion and left shoulder flexion was subjected to caesarean section. Following surgery the dam was maintained on antibiotics, fluids and other supportive therapy. The animal was reported to have recovered uneventfully.

\section{Introduction}

Dystocia may be defined as difficulty in parturition as opposed to normal parturition. Dystocia is often affected by several factors such as breed, parity of dam, sex of calf, birth weight of calf, pelvic size of dam, gestation length, nutrition, year and season of calving (Singh et al., 2019). The causes of dystocia can be broadly classified as maternal or foetal in origin. The maternal factors that often lead to dystocia are inadequacies in birth canal or deficiency of expulsive forces. Inadequate space in the birth canal is the most common cause for dystocia in primiparous animals or heifers (Hickson et al., 2006). A 2 year old cross bred holstein friesian heifer presented with delay in parturition was diagnosed as dystocia due to foeto maternal disproportion and left shoulder flexion and was subjected to caesarean section.

The animal was maintained on antibiotics, fluids and other supportive therapy post operatively. The animal was reported to have recovered uneventfully. 


\section{Materials and Methods}

\section{Ananmesis, \\ Clinico-gyanecological examination and Diagnosis}

A 2 year old cross bred holstein friesian cow was presented with the complaint of difficulty in parturition. The animal started showing signs of parturition since last six hours and one of its forelimb and head was seen. The animal was examined by another veterinarian and foeto maternal disproportion and left shoulder flexion was noticed. Since the calf was found dead, decapitation was done by the veterinarian in order to correct the presentation and remove the foetus. The inadequate space in the pelvis hindered the correction. As the condition was diagonosed as foeto maternal disproportion with left shoulder flexion the animal was subjected to caesarean section.

\section{Anaesthesia and control}

The surgical procedure was done under xylazine hydrochloride sedation at the rate of $0.1 \mathrm{mg}$ per kilogram bodyweight and regional anaesthesia was accomplished by inverted $\mathrm{L}$ block using $2 \%$ lignocaine.

\section{Surgical Procedure}

The animal was placed in right lateral recumbency and the surgical site was clipped shaved and prepared for aseptic surgery. An Oblique incision was made in the left lower flank downward and forward. The incision was deepened by incising through the muscle layers and peritoneum to reach the abdominal cavity. The uterus was exteriorized and a knick incision was made in the uterus which was extended with scissors. The foetus was tracted out gently. The uterine opening was closed with catgut 1 in double layer inversion suture pattern, thereafter muscles and skin was apposed in routine manner. Polyglycolic acid 1 suture was used for apposing muscle layers and Nylon for skin. Post operatively the animal was maintained on fluids, antibiotics and other supportive therapy for five days.

\section{Results and Discussion}

The holstein friesian cross bred heifer that was presented with dystocia was subjected to caesarean section following diagnosis. The animal was maintained on antibiotics, fluid and other supportive therapy post operatively for five days. The animal was reported to have recovered uneventfully.

Among the domestic animals dystocia is most commonly seen in cattle and buffaloes (Purohit et al., 2011). The causes of dystocia are numerous and can be either maternal or foetal in origin. Dystocia due to foeto maternal disproportion is most commonly seen in case of heifers. (Hickson et al., 2006). Pelvic abnormalities of the dam that can result in dystocia include small size of pelvis, pelvis deformities or exostoses, osteomalacia, hypoplasia of vagina and vulva. (Purohit $e t$ al., 2011). Narrow pelvis as cause of dystocia in cows was reported by Jeengar et al., 2015.

Fig.1 Surgical Site

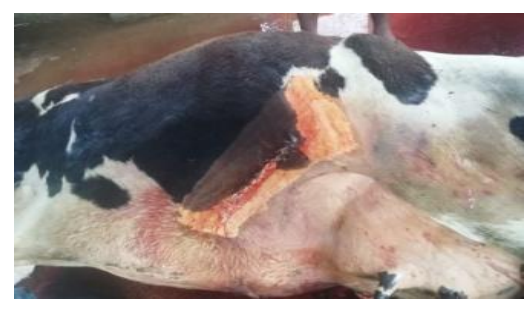


Fig.2 Calf retrieved from the dam

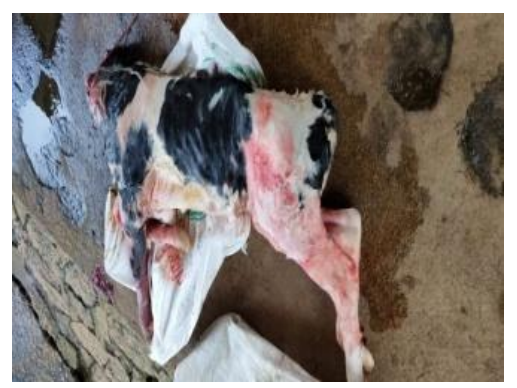

Fig.3 Fifth day Post operative

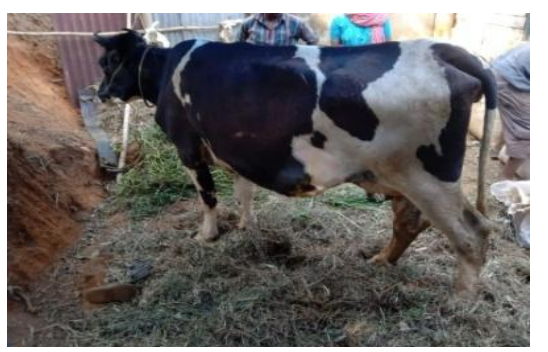

Dystocia due to foetomaternal disproption often needs caesarean section. Caesarean section is adopted in order to save the life and to maintain the future fertility of the dam (Newman and Anderson, 2005). There are eight sites which are generally preferred for performing the cesarean section i.e. standing left paralumbar celieotomy, standing right paralumbar celiotomy, recumbent ventral paralumbar celiotomy, recumbent ventral midline celiotomy, recumbent ventral paramedian celiotomy, ventrolateral celiotomy and standing left oblique celiotomy (Schultz et al., 2008). The most common indications that requires caesarean section to be performed are immature heifers, pelvis deformities, failure of cervical dilation, uncorrectable uterine torsion, uterine tear, hydrops, prepartum paralysis, absolute oversized fetus, malposition and pathological foetal conditions (Campbell and Fubini, 1990).

Although many sites are cited for performing cesarean section left oblique ventrolateral site is the most commonly adopted site as their occurs minimum post operative contaminations and lesser post operative complications (Verma et al., 1974 and Singh et al., 1978).

\section{Acknowledgement}

The author would like to acknowledge Director, Kerala Animal husbandry Department and District Animal Husbandry Office, Idukki for providing the facilities for the successful completion of the work.

\section{References}

Campbell, M.E. and Fubini, S.L. 1990. Indications and surgical approaches for cesarean section in cattle. Compend. Contin. Educ. Pract. Vet. 12:285-292.

Hickson, R. E, Morris, S. T, Kenyon, P. R. and Villalobos, N. L.2006. Dystocia in beef heifers: A review of genetic and nutritional influences. New Zealand Vet. J. 54(6). 256-264.

Jeengar, K, Purohit, G. N, Mehta, J. S, Chowdhary, V. and Nirwan L. K. 2015. 
A retrospective study on incidence of dystocia in cattle and buffaloes at referral center. Theriogenology Insight: 5(1): 41-45.

Newman, K.D. and Anderson, D.E. 2005. Cesarean section in cows. Vet Clinics Food Anim. 21:73-100.

Purohit, G. N, Barolia, Y, Shekhar, C. and Kumar, P. 2011. Maternal dystocia in cows and buffaloes: A Review. Open J. Ani. Sci. 1. 41-53.

Schultz, L. G., Tyler, J. W., Moll, D. H. and Constantinescu, G.M. 2008. Surgical approaches for cesarean section in cattle. Can. Vet. J. 49(6): 565-568.

Singh, J., Prasad, B. and Rathor, S.S. 1978. Torsio uteri in buffaloes (Bubalusbubalis)- An analysis of 65 cases. Indian Vet. J. 55:161-165.

Singh M, Sharma, A. and Kumar, P. Bovine dystocia -An overview. 2019. J. Vet. Sci. and Zoology. 1(1).

Verma, S.K., Manohar, M. and Tyagi, R.P.S. 1974. Cesarean section in bovines: A clinical study. Indian Vet. J. 51:471479.

\section{How to cite this article:}

Nijin Jos, B. M. 2020. Surgical Management of Dystocia in a Cross Bred Holstein Friesian Heifer by Caesarean Section- A Case Report. Int.J.Curr.Microbiol.App.Sci. 9(07): 3928-3931. doi: https://doi.org/10.20546/ijcmas.2020.907.460 